\title{
Occult Lung Carcinoma
}

National Cancer Institute

\section{Source}

National Cancer Institute. Occult Lung Carcinoma. NCI Thesaurus. Code C5641.

A lung carcinoma detectable by sputum cytology or bronchial washings only. The primary tumor is undetectable radiographically or during bronchoscopy; therefore, it can not be assessed 